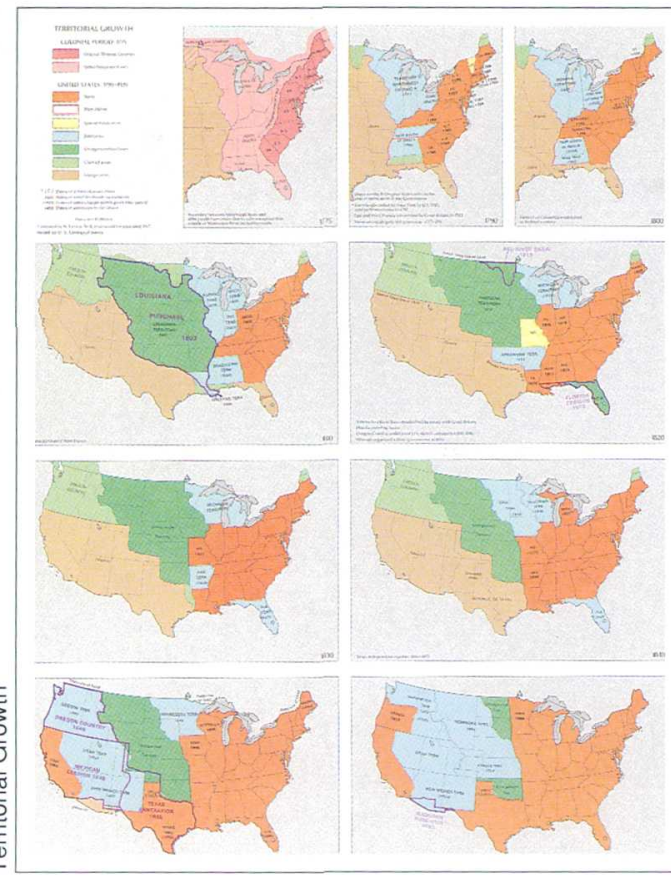

The National Atlas of the United States of America was published by the U.S. Geological Survey in 1970. Its 765 maps and charts are on 335 14- by 19 inch pages. Many of the maps span facing pages.

It's worth a quick trip to the library just to leaf through all 335 pages of this book. Rapid scanning of its thematic maps yields rich insights to the geography of issues of continuing national interest. On most maps, the geographic patterns are still valid, though the data are not current.

The atlas is out of print, but many of its maps can be purchased separately. Maps that span facing pages in the atlas are printed on one sheet. The maps dated fter 1970 are either revisions of original atlas maps, or new maps published in atlas format. The titles of the separate maps are listed here.

\section{Thematic maps of the United State}

Sheet size is 28 by 19 inches. Most of the maps have a scale of 1:7,500,000, but a few have scales that range between 1:17,000,000 and 1:34,000,000. Most of the maps include thematic data on the conterminous United States, Alaska, and Hawaii.

\section{Relief and physiography}

United States Shaded Relief (1969)

Alaska Shaded Relief (1969)

Physiography and Physiographic Divisions (1968)

Land-Surface Form [Alaska] (1968)

Classes of Land-Surface Form (1964)

U.S. Satellite View (1990)

\section{Geology}

Geology (1966)

Surficial Geology (1979)

Tectonic Features (1967)

Tectonic Features [Alaska] (1968)

Engineering Aspects of Karst (1984

\section{Coastal environment}

Coastal Erosion and Accretion (1985)

Coastal Hazards (1985)

Climate

Monthly Sunshine (1965)

Annual Sunshine, Evaporation,

and Solar Radiation (1969)

Monthly Average Temperature (1965)

Monthly Minimum Temperature (1965)

Monthly Maximum Temperature (1965)

\section{Hydrology}

Surface Water (1965) (1988)

Soils and vegetation

Soils (1985)

Potential Natural Vegetation (1985)

Major Forest Types (1987, revisions to Alaska only)

Ecology

Principal Federal Lands Where Exploration

and Development of Mineral Resources

are Restricted (1981)

National Wilderness Preservation

System (1987) (Sheet size 42 by 28 inches:

scale $1: 5,000,000)$

Networks of Ecological Research Areas (1983)

\section{Transportation}

Highways (1987)

\title{
National Atlas Maps
}

U.S. Department of the Interio

U.S. Geological Survey

Earth Science

Information Center (ESIC)

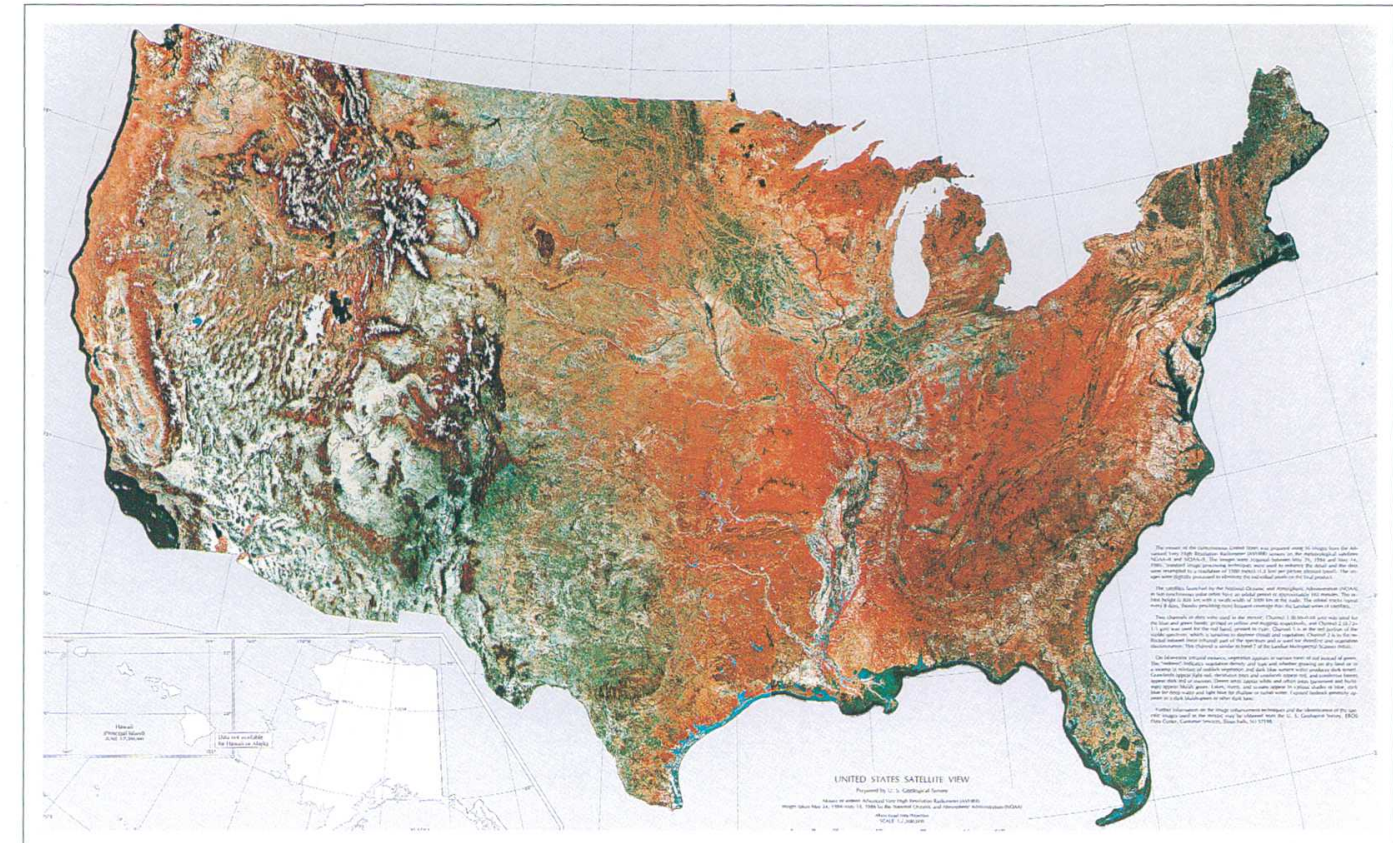

U.S. Satellite View (1990)

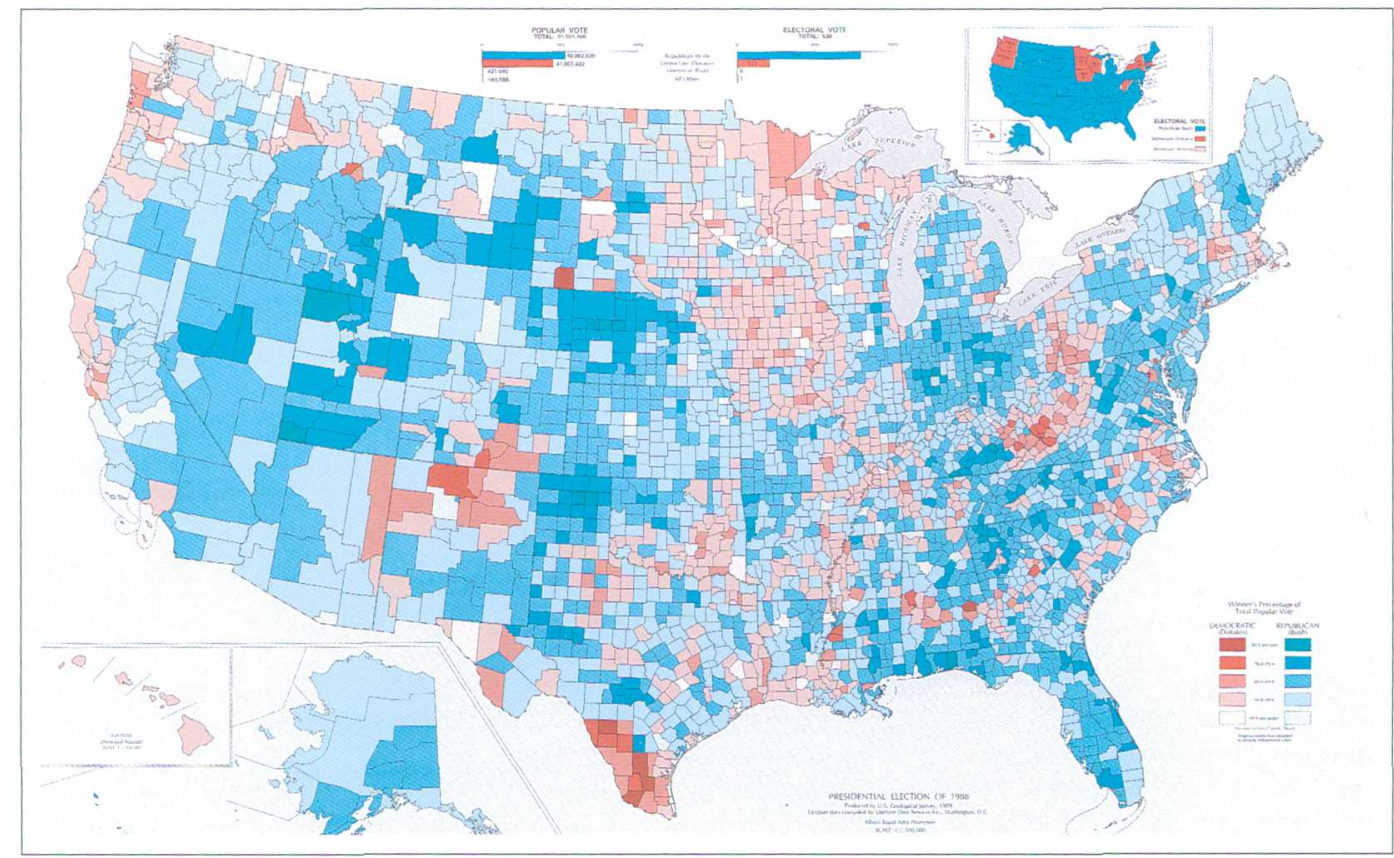

Presidential Election of 1988 (1989)

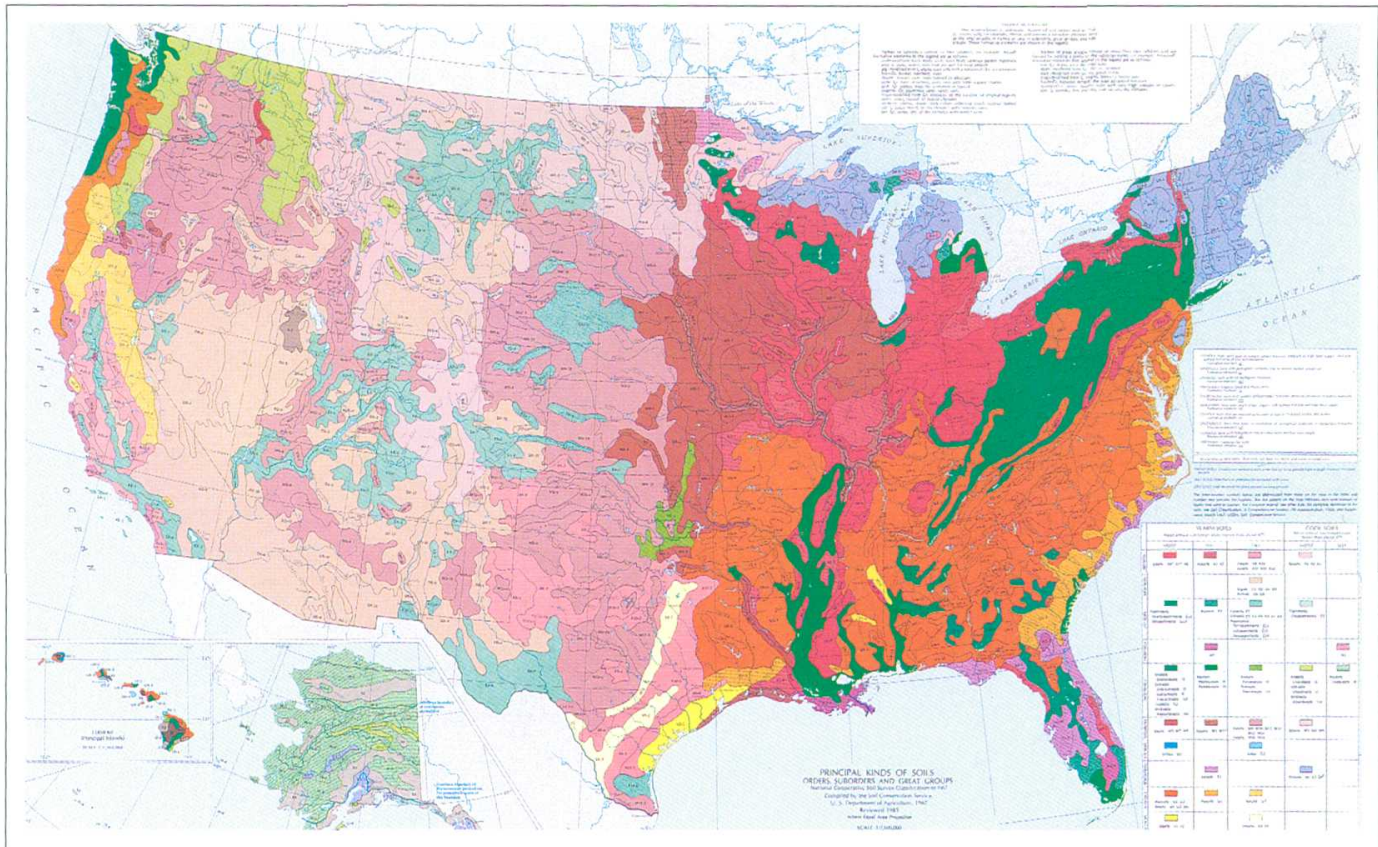




\section{Population}

Early Indian Tribes, Culture Areas,

and Linguistic Stocks (1967)

Population Distribution,

Urban and Rural: 1960

Population Distribution,

Urban and Rural: 1970

Population (1970)

\section{Political history and administration}

Territorial Growth (1986)

Federal Lands (1968)

Counties (1987)

Congressional Districts for the 100th

Congress (1987)

Presidential Elections, 1789-1968/1972-1984

Electing the President, 1789-1988 (map booklet)

Presidential Election of 1988 (1989)

\section{National Energy Transportation Maps}

This series of 19 thematic maps was prepared by the U.S. Geological Survey and originally published as part of a report by the Committee on Energy and Natural Resources and the Committee on Commerce, Science, and Transportation, U.S. Senate.

The transportation data were provided by the Congessional Research Service, Library of Congress.

The maps are in National Atlas thematic map format.

Natural Gas Movement by Pipelines (1974)

Coal Movement by Railroads (1974)

Coal Movement by Highways (1974

Coal Movement by Water (1974)

Total Coal Movement (1974)

Coal Resources and Distribution (1974)

Crude Oil Movement by Pipelines (1974)

Crude Oil Movement by Water (1974)
Petroleum Products Movement by Pipelines (1974) Petroleum Products Movement by Water (1974) Total Crude Oil Movement (1974)

Total Petroleum Products Movement (1974)

Total Petroleum Movement (1974)

Electric Power Transmission (1974

Nuclear Fuel Materials Movement by Highways (Truckloads) (1975)

Nuclear Fuel Materials Movement by Highways (BTU) (1975)

Pipeline Transportation Systems (1974)

Railroad, Highway, and Water Transportation

Systems (1974)

Total Interstate Energy Movement (1974)

\section{Reference map}

U.S. General Reference (1973)

This 28- by 19-inch map shows-

- Names of populated places and railroads in black

- Areas of cities with populations of more than

1 million in yellow

- State boundaries and names highlighted in gray

- Highways and ferry routes in red

- Water features in blue

- Names of physical features and shaded relief base in brown

- The conterminous 48 States and Hawaii at a scale of 1:7,500,000 (one inch represents 118.4 miles) - Alaska at a scale of 1:17,000,000 (one inch represents 268.3 miles)

Also available are transparent plastic overlays at various scales to permit overlaying reference information on thematic maps.

\section{Sectional reference maps}

A series of multicolor planimetric (no contours) maps (also available singly) shows the United States in 21 sections at a scale of 1:2,000,000 ( 1 inch represents 31.5 miles). Content is similar to that of the U.S. General Reference without shaded relief, but is portrayed in greater detail; national park and forest lands, wildlife refuges, and Indian reservations are also shown.

Except for Alaska, California, Montana, and Texas, the sectional maps have been designed so that each State is shown in its entirety on one sheet.

Each map is printed on one side of a 28 - by 19 -inch sheet.

Northeastern States (1972)

Maine, New Hampshire, Vermont, New York,

Massachusetts, Connecticut, Rhode Island

Middle Atlantic States (1972)

Pennsylvania, New Jersey, Delaware, Maryland,

Virginia, West Virginia, Ohio

Southeastern States (1972)

North Carolina, South Carolina, Georgia

\section{Florida (1972)}

Southern Mississippi Valley States (1972)

Alabama, Mississippi, Louisiana, Arkansas,

Tennessee

Central Mississippi Valley States (1972)

Indiana, Illinois, Iowa, Missouri, Kentucky

Northern Great Lakes States (1972)

Michigan, Wisconsin, Minnesota

Northern Plains States (1972)

North Dakota, South Dakota, Eastern Montana,

Wyoming

Central Plains States (1973)

Nebraska, Colorado, Kansas

Southern Plains States (1973

Oklahoma, Northern Texas

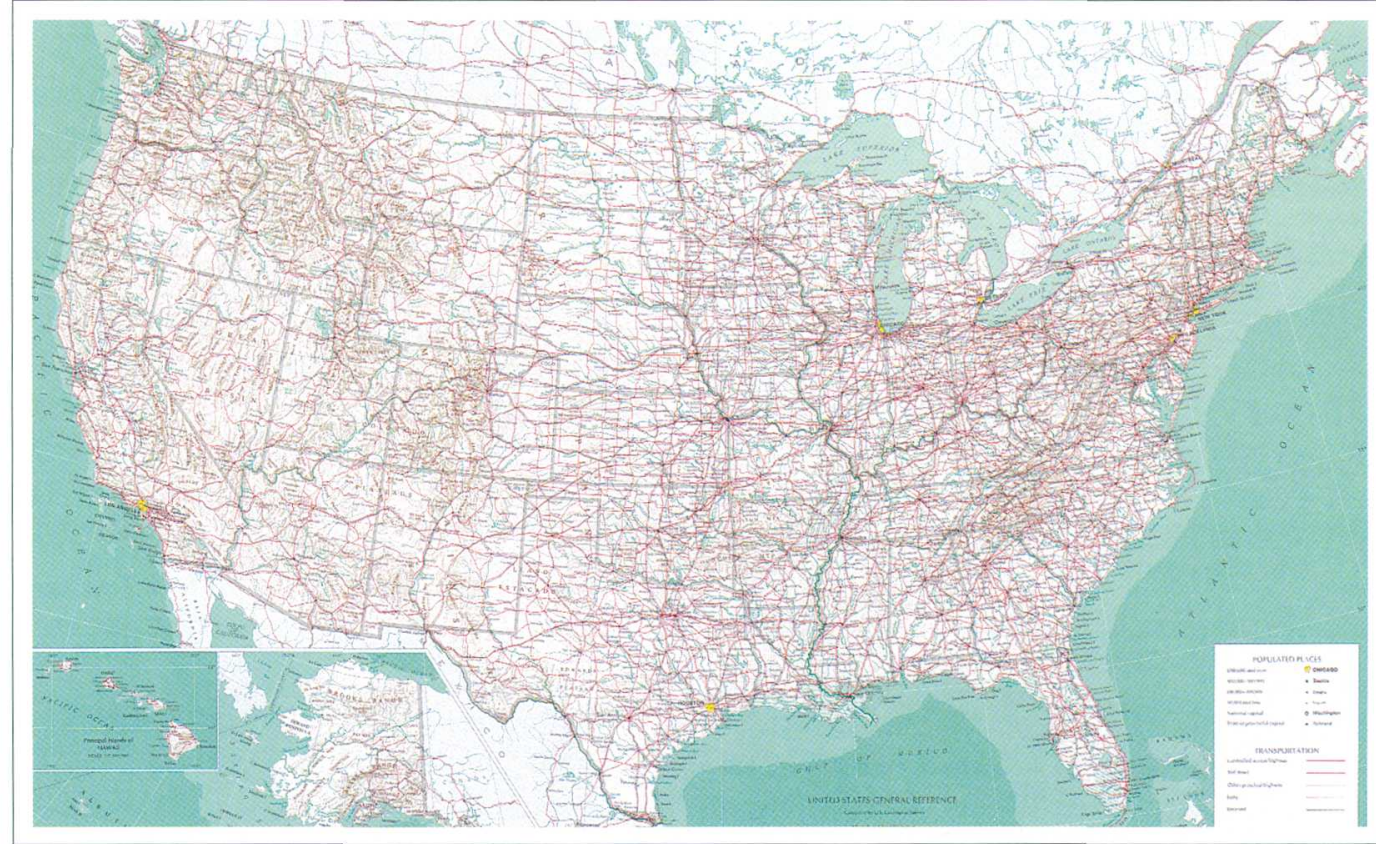

U.S. General Reference (1973)

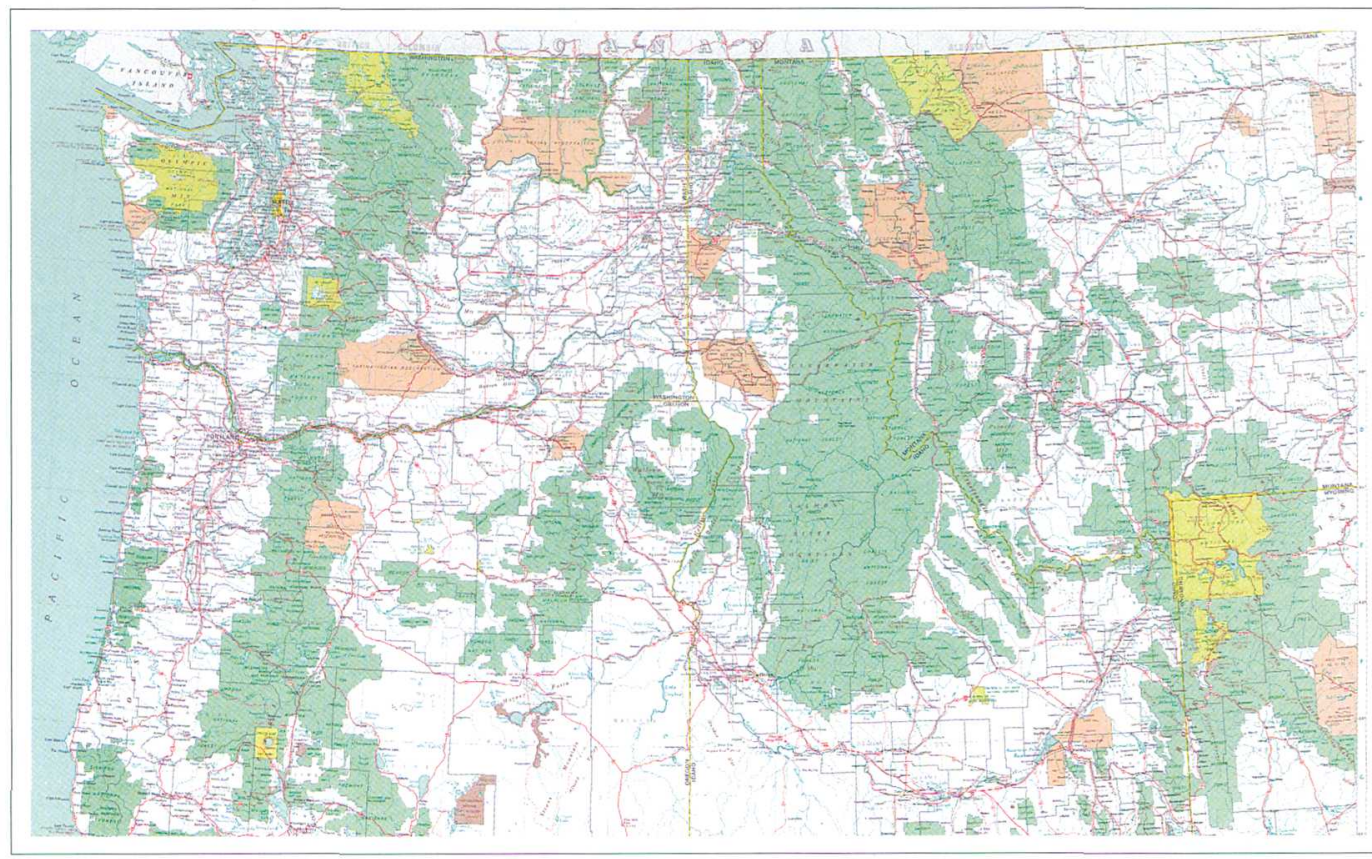

Northwestern States (1973)

Southern Texas (1973)

Arizona and New Mexico (1973)

Southern California (1973)

Central Pacific States (1972)

Northern California, Nevada, Utah

Northwestern States (1973

Western Montana, Idaho, Oregon, Washington

Hawaiian Islands (1972)

Southeastern Alaska (1972)

Central Alaska (1973)

Northern Alaska (1973)

Southwestern Alaska (1973)

Aleutian Islands (1973)
How to order National Atlas Maps

To receive an order form and current list of all National Atlas Maps, contact any ESIC office, or call 1-800-USA-MAPS.

Maps of the United States published or distributed by the Geological Survey can be purchased from: USGS Map Sales

Box 25286

Denver, CO 80225

(303) 236-7477

Local and regional information about USGS maps and publications can be acquired from: 